\title{
ASPECTOS TÉCNICOS DA LAVRA DO PEGMATITO “ALTO” FEIO, PEDRA LAVRADA, PARAÍBA
}

\author{
D. R. SOARES*, F. A. S. GONZAGA, A. C. M. FERREIRA+, H. K. C.CAITANO, A. B. FARIAS e D. B. SOUSA \\ +in memorian \\ IFPB, campus Campina Grande/Núcleo de Estudos de Pegmatitos (N-PEG) \\ dwightsoares@yahoo.com.br*
}

Artigo submetido em julho/2015 e aceito em janeiro/2016

DOI: $10.15628 /$ holos.2016.3248

\section{RESUMO}

A Província Pegmatítica da Borborema (PPB) notabilizouse ao final da II Guerra Mundial por ser importante fonte de $\mathrm{Nb}$-Ta e Be para os países aliados. Nessa época de intensa produção de bens minerais definiu-se, pioneiramente, a estrutura interna de pegmatitos graníticos. A partir do entendimento da estrutura interna foi possível determinar métodos de lavra para pegmatitos da região. Normalmente nos pegmatitos homogêneos (sem zoneamento interno e de pequenas dimensões) realiza-se a extração total do corpo. Nos pegmatitos heterogêneos (com zoneamento interno zonas I, II, III e IV) geralmente extrai-se a zona III (unidade onde ocorrem minerais econômicos). O Pegmatito Alto Feio, localizado em Pedra Lavrada, Paraíba, é um pegmatito diferenciado com grande núcleo (zona IV) de quartzo róseo de excel ente qualidade. Por esse motivo a lavra ocorre nas zonas III e IV.

PALAVRAS-CHAVE: Pegmatito Alto Feio, Lavra de pegmatitos, Província Pegmatítica da Borborema.

\section{TECHNICAL ASPECTS OF EXPLOITATION OF THE “ALTO FEIO PEGMATITE, PEDRA LAVRADA, PARAÍBA}

\begin{abstract}
The Borborema Pegmatite Province (BPP) is notable to the end of World War II to be important source of $\mathrm{Nb}-\mathrm{Ta}$ and $\mathrm{Be}$ for the allied countries. At this time of intense production of mineral goods set up, innovatively, the internal structure of granitic pegmatites. From the understanding of the internal structure could be determined mining methods to pegmatites in the area. Usually in homogenous pegmatite (no internal zoning
\end{abstract}

and small dimensions) is performed at full extension of the body. In heterogeneous pegmatite (with internal zoning - zones I, II, III and IV) generally extracted zone III (where there drive economic minerals). The pegmatite Alto Feio, located in Pedra Lavrada, Paraíba, is a differentiated pegmatite with largecore (zone IV) of rose quartz excellent quality. Therefore exploration works occurs in zones III and IV.

KEYWORDS: Alto Feio pegmatite, pegmatite mining, Borborema Pegmatite Province. 


\section{INTRODUÇÃO}

A Província Pegmatítica da Borborema (PPB), definida por SCORZA (1944) é uma região de ocorrência de corpos pegmatíticos classificados como de elementos raros, enriquecidos principalmente em $\mathrm{Be}, \mathrm{Nb}-\mathrm{Ta}$ e $\mathrm{Li}$, além de ser produtora de minerais industriais e gemas diversas.

Os pegmatitos da PPB são, em sua maioria, corpos pequenos, nem sempre justificando grandes investimentos. Por isso a maioria dos corpos são trabalhados por garimpeiros. A produção de minérios em pequena escala realizada por garimpeiros é conhecida como "mineração artesanal e de pequena escala". São operações a céu aberto ou subterrâneas (próximas à superfície), normalmente confinadas a pequenas aberturas como acessos para trabalhos subterrâneos (MELO, 2011). Em todos os países do mundo, os trabalhos de extração de minérios pegmatíticos têm cunho artesanal. As condições de trabalho, a falta de infraestrutura, o pouco ou nenhum apoio profissional e os rigores da natureza fazem essa atividade ser caracterizada como de alto risco.

O presente trabalho traz um estudo preliminar sobre a lavra de quartzo róseo realizada no pegmatito Alto Feio, localizado em Pedra Lavrada, Estado da Paraíba. Trata-se de um corpo pegmatítico com grande núcleo de quartzo róseo que é utilizado como material ornamental.

\section{REVISÃO BIBLIOGRÁFICA}

O termo pegmatito foi proposto inicialmente pelo mineralogista francês Haüy no início do século XIX para designar o que atualmente se conhece por granito gráfico (JAHNS, 1955), ou seja, intercrescimento geométrico cuneiforme epitaxial entre quartzo e feldspato. Posteriormente o vocábulo tornou-se mais abrangente, incluindo rochas de granulometria muito grosseira, onde o granito gráfico constitui uma parte delas.

Conforme LONDON (1996) pegmatitos graníticos são caracterizados pela presença de fases minerais de tamanho extremamente grande (que o distinguem das demais rochas intrusivas como granito, sienito, diorito, etc.), pela heterogeneidade, incluindo abrupta variação no tamanho do grão ou na mineralogia, anisotropia de trama e uma extensa gama de morfologia de cristais (esqueletal, gráfica, euedral), podendo ser gerado por magmas de todas composições.

A PPB é historicamente importante como fonte de Ta-Nbe Be. Durante a II Guerra Mundial houve um extraordinário aumento da demanda por matérias-primas minerais como berilo e tantalita, para suprir as necessidades dos países aliados. A PPB tornou-se, então, uma região de excepcional importância estratégica. Conforme ROLFF (1946b), o município de Picuí, Paraíba chegou a produzir $20 \%$ da produção mundial de tantalita e entre 8 e $10 \%$ da produção mundial de berilo. Nesse período, cerca de 450 pegmatitos mineralizados foram lavrados simultaneamente na região. Neste ambiente de excepcional produção foram produzidos alguns dos mais importantes trabalhos científicos abordando os pegmatitos da PPB. Entre eles podem ser citados: JOHNSTON Jr. (1945a e 1945b); ROLFF (1946a, 1946b e 1946c), SCORZA (1944). Vale salientar que a classificação pioneira da estrutura interna dos pegmatitos, a nível mundial, foi realizada por JOHNSTON Jr. nos pegmatitos da PPB, descrita em seus dois trabalhos de 1945. CAMERON et al. (1949) estudando pegmatitos dos Estados Unidos, propuseram um zoneamento primário semelhante ao proposto por JOHNSTON Jr. (op. cit.), cabendo entretanto a Cameron e colaboradores, o mérito da generalização da estrutura zonada em pegmatitos graníticos. 
Os pegmatitos da PPB, além de serem portadores de minerais comuns em pegmatitos enriquecidos em elemento raros, tais como columbita/tantalita, berilo, turmalina, contêm também minerais de ocorrência restrita, ou mesmo raros, tais como simpsonita, euclásio, tantalaeschinita, parabariomicrolita, alumotantita. Alguns minerais, tais como arrojadita, tantalaeschinita, parabariomicrolita, serrabrancaíta e fluornatromicrolita, foram descritos pioneiramente na PPB.

O pegmatito Alto Feio é conhecido desde os anos 20 do século passado, provavelmente entre os anos 1926 e 1929, quando se iniciaram os trabalhos para extração de mica (ALMEIDA, 1946). No período da II Guerra Mundial, devido principalmente ao esforço de guerra empreendido pelos Estados Unidos, esse corpo pegmatítico, assim como os demais pegmatitos da região, foram trabalhados exclusivamente para extração de tantalita e berilo, materiais estratégicos. Nesse período também foi extraído bismutita, como subproduto. Posteriormente, passou a ser trabalhado para extração de quartzo róseo.

Localiza-se a aproximadamente $800 \mathrm{~m}$ a NE da cidade de Pedra Lavrada, no contato entre o xisto Seridó e um granito cinza. Tem direção de $\mathrm{N} 65^{\circ} \mathrm{E}$, com mergulho subvertical para NW. Suas dimensões aflorantes são da ordem de $500 \mathrm{~m}$ de extensão por 100 de espessura máxima. De acordo com JOHNSTON Jr, (1945b) o pegmatito Alto Feio é um corpo heterogêneo constituído de zonas I, II, III e IV (núcleo). Sua paragênese mineral inclui tantalita/columbita, berilo, bismutita, zircão, turmalina (negra e verde), arrojadita e quartzo róseo. Minerais econômicos como tantalita/columbita e berilo ocorrem geralmente na Zona III ou no contato desta com a zona IV, o que geralmente acontece nos pegmatitos zonados da região.

Diversos trabalhos que abordam a mineralogia, geologia e lavra dos pegmatitos da PPB e que descrevem o pegmatito Alto Feio, foram produzidos em épocas diversas (ALMEIDA, 1941 e 1946; SCORZA, 1944, JOHNSTON Jr. 1945a e 1945b, ROLFF, 1946a, 1946b, 1946c e 1951; MOORE, 1945; PIRES, 1998, entre outros). Nos últimos anos não houve produção bibliográfica abordando aspectos da lavra ou da geologia/mineralogia desse pegmatito.

A partir da classificação proposta por CERNY \& ERCIT (2005), BEURLEN et al. (2008) classificaram o pegmatito Alto Feio como da classe elementos raros, tipo berilo. A paragênese mineral desse pegmatito leva-nos a inseri-lo na subclasse berilo-columbita-fosfato de CERNY \& ERCIT (2005).

\section{METODOLOGIA}

O pegmatito Alto Feio foi escolhido para esse estudo devido sua singularidade. É o único corpo na região que apresenta volumoso núcleo de quartzo róseo, aproveitado para fins ornamentais. Sua lavra ocorre nas zonas IIII e IV, diferente da lavra de outros pegmatitos da PPB, onde os trabalhos se concentram normalmente na zona III (unidade econômica dos pegmatitos).

Com o propósito de entender a lavra desse pegmatito foram consultados trabalhos técnicos sobre o assunto, de diversos momentos históricos, com ênfase para alguns artigos publicados durante a Segunda Guerra Mundial, época em que se publicou muitos trabalhos técnicos importantes. Também foram consultadas Teses de Doutorado e Dissertações de Mestrado abordando o tema.

Atualmente o pegmatito encontra-se quase que totalmente encoberto por pilhas de rejeito que foi se acumulando ao longo dos anos de trabalho. Por esse motivo, optou-se por consultar dados da geologia e da lavra fornecida por diversos autores, associando-se esses dados aos 
aspectos observados durante as visitas de campo realizadas para observar, in loco, os aspectos técnicos da lavra do pegmatito. No desenvolvimento da pesquisa utilizou-se a seguinte sequência de ações:

- Levantamento bibliográfico: consulta em artigos publicados no Brasil e no exterior;

- Viagens de campo: reconhecimento do pegmatito e observações sobre sua paragênese mineral e a lavra;

- Redação do texto: procurou-se desenvolver o texto em uma sequência lógica e obedecendo as normas do periódico HOLOS.

\section{ASPECTOS GEOLÓGICOS REGIONAIS}

A Província Pegmatítica da Borborema (PPB), designação de SCORZA (1944) insere-se em partes dos Estados da Paraíba e Rio Grande do Norte, delimitada pelas coordenadas geográficas $5^{0} 30^{\prime}$ e $7^{0} 15^{\prime}$ de latitude $S$ e $35^{\circ} 45^{\prime}$ e $37^{0} 15^{\prime}$ de longitude $W$, correspondendo à parte central da Faixa de Dobramentos Seridó (Figura 1).

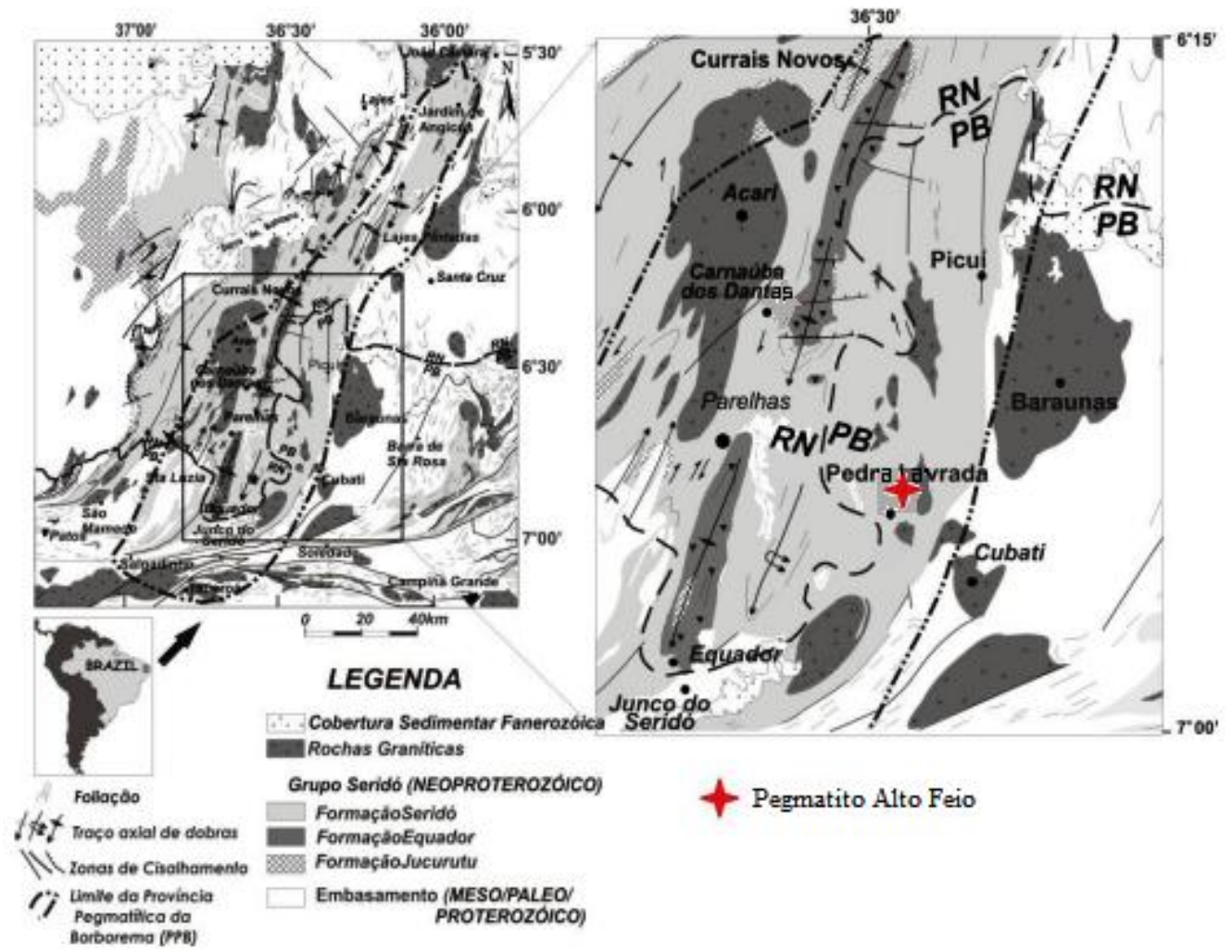

Figura 1: Mapa geológico simplificado da região do Seridó, com delimitação da PPB, proposta por SOARES (2004)

A Faixa de Dobramentos Seridó, ou simplesmente Faixa Seridó é constituída de um embasamento gnáissico-granítico-migmatítico paleoproterozóico e uma sequência supracrustal metavulcanossedimentar neoproterozóica, designada por Grupo Seridó, constituída, da base para o topo, de:

- Formação Jucurutu - constituída de paragnaisses quartzo feldspáticos com pouca biotita \pm muscovita \pm epidoto. 
- Formação Equador - constituída basicamente por muscovita-quartzitos, metarcósios e metaconglomerados.

- Formação Seridó - é a unidade estratigráfica mais típica da região, constituída por uma sequência pelítica (com granada-biotita xisto como litologia dominante) com variações para psamítica (muscovita-quartzitos intercalados na sequência pelítica) e carbonática.

É notável a presença de corpos de natureza granítica em toda a faixa Seridó, intrudindo-se em várias unidades estratigráficas, além de pegmatitos graníticos, muitos deles mineralizados principalmente em Be, Ta-Nb, Li, Sn. Muitos desses pegmatitos graníticos são portadores da excêntrica e inigualável turmalina Paraíba, elbaíta de excepcional cor azul anil, de altíssimo valor comercial.

BEURLEN et al. (2008) estimaram em aproximadamente 750 o número de pegmatitos mineralizados na PPB. Conforme BEURLEN et al. (2014), 80\% dos pegmatitos mineralizados estão inseridos na Formação Seridó, $10 \%$ na Formação Equador e os $10 \%$ restantes, em outras litologias da região.

\section{ASPECTOS DA LAVRA - DISCUSSÕES}

JOHNSTON Jr. (1945a e 1945b), tomando como base a estrutura interna dos pegmatitos da região, classificou-os em homogêneos (sem zoneamento mineralógico/textural) e heterogêneos (com zoneamento), com zonas I, II, III e IV, a partir da borda em direção ao centro.

De acordo com esse autor os pegmatitos homogêneos são de pequenas dimensões e pouco mineralizados e os pegmatitos heterogêneos são economicamente mais importantes, com as principais mineralizações ocorrendo na zona III.

Nos pegmatitos homogêneos realiza-se a lavra total, ou seja, desmonta-se todo o corpo pegmatítico, aproveitando-se os minerais de valor econômico. De acordo com MOORE (1945), nos pegmatitos heterogêneos (zonados) normalmente extrai-se somente a zona III (zona geralmente econômica do pegmatito, onde ocorrem nióbio-tantalatos, berilos, turmalinas coloridas, entre outros). Esta metodologia deixa muito a desejar, pois é muito agressiva ao meio ambiente e deixa muito subproduto sem aproveitamento. Ainda nos dias de hoje, utiliza-se essa metodologia.

O pegmatito Alto Feio é um corpo pegmatítico zonado, com volumoso núcleo de quartzo, em parte, róseo. Devido a essa característica especial sua lavra é diferenciada dos demais pegmatitos da região, com extração de minerais da zona III e da zona IV.

Atualmente o pegmatito Alto Feio encontra-se quase totalmente aterrado, o que impossibilita a observação de sua estrutura interna. Conforme Johnston Jr. (1945a e 1945b) e Almeida (1946) e observações locais, o zoneamento do pegmatito é constituído de

Zona I - quando exposta é bem desenvolvida, constituída de feldspato, quertzo e bastante muscovita;

Zona II - ocupa cerca de metade da área do pegmatito, constituída de feldspato e e muita turmalina negra;

Zona III - grandes cristais de microclima, chegando a pesar até 100 toneladas, berilo, tantalita, turmalina verde, berilo, albita e alguns fosfatos. 
Zona IV - núcleo de quartzo róseo e leitoso, descontínuo, provavelmente devido à tectônica local, exibindo na porção superior ao núcleo, fraturas de descompressão (horizontais), geradas por alívio de pressão. É comum se observar faixas brancas em blocos de quartzo róseo devido à tectônica. Essas faixas, quando observadas ao microscópio, mostram-se completamente cisalhadas.

Conforme JOHNSTON Jr. (1945a e 1945b) entre os anos de 1938 e 1945 foram extraídos do Alto Feio cerca de 700 toneladas de berilo e 4 toneladas de tantalita. Atualmente não se dispõe de dados de produção do quartzo róseo e dos feldspatos extraídos no pegmatito.

Atualmente o pegmatito Alto Feio está sendo trabalhado para a extração de quartzo róseo e quartzo leitoso (zona IV) e albita (zona III), de forma artesanal, sem nenhuma orientação técnica. O quartzo róseo extraído é de excelente qualidade, apresentando tonalidades fortes. Alguns pequenos fragmentos de quartzo róseo apresentam qualidade gemológica, embora, seja pouco utilizado como gema, devido seu baixo valor. A albita mostra certo nível de alteração e está associada com fosfatos tipo arrojadita.

A lavra do pegmatito Alto Feio se desenvolve a céu aberto. Foram abertas bancadas com dimensões aproximadas de $10 \mathrm{~m} \times 10 \mathrm{~m}$ e profundidades variáveis, localizadas nos limites da zona III a zona IV (núcleo de quartzo). Observações locais indicam que o aprofundamento indefinido dessas banquetas tornará a lavra inviável por razões técnicas (dificuldades de acesso na retirada do material).

Os trabalhos de perfuração são realizados manualmente utilizando-se explosivos artesanais para o desmonte, com pouca eficiência. O quartzo róseo, após desmontado, é fragmentado manualmente com marretas e separado por cor e tamanho, formando diversos lotes (Figura 2), expostos ao sol, sujeito à perda da coloração rósea.

Quando expostos ao sol por muito tempo, a maioria dos fragmentos dos lotes fica descolorido, adquirindo cor branca leitosa, perdendo valor comercial. A coloração do quartzo róseo é proveniente, em parte, de defeitos na estrutura (centros de cores). Por isso, quando excitados pela radiação solar tornam-se leitosos.

Nos pegmatitos da PPB, o quartzo normalmente não ocorre sob a forma de cristais bem formados, exceto quando ocorre em pockets. Em um mesmo núcleo pode ocorrer mais de um tipo de quartzo, sendo o leitoso o mais comum (DA SILVA \& DANTAS, 1984). Núcleos volumosos de quartzo róseo, como o do pegmatito Alto Feio são raros na região.

Na maioria dos países, inclusive no Brasil, a extração de Be, Ta-Nb e Li em pegmatitos ocorre em pequena escala. Conforme CERNY (1991) a mineração de pegmatitos em pequena escala (comumente em escala familiar) contribui significantemente para a produção mundial de certas commodities minerais. Na PPB, a grande maioria dos pegmatitos é trabalhada por garimpeiros, de modo artesanal, sem nenhuma orientação técnica. 


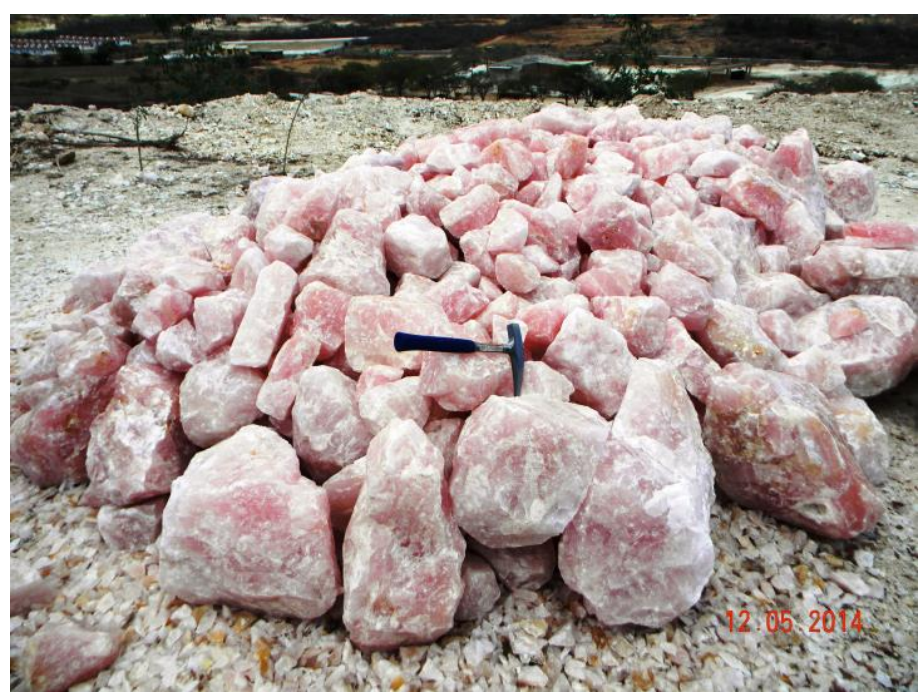

Figura 2: Lote de quartzo róseo do pegmatito Alto Feio, pronto para comercialização. (Foto: F. Gonzaga).

Os outros materiais extraídos não são separados por granulometria; são apenas fragmentados para redução de tamanho. Garimpeiros que trabalham no pegmatito informaram que o quartzo róseo está se exaurindo, inviabilizando toda a lavra. Observações de campo, no entanto, indicam que ainda existe razoável quantidade de quartzo róseo e branco leitoso, o que pode prolongar a lavra do pegmatito por alguns anos.

Necessita-se realizar cuidadosa avaliação do pegmatito, iniciando-se pela remoção do rejeito, abertura de trincheiras e possivelmente poços de pesquisa, visando determinar seu potencial econômico, com possibilidades de extração de outros minerais de interesse econômico. Isso, no entanto é muito oneroso e necessitaria de auxílio do poder público ou de alguma empresa privada interessada em investir no setor.

\section{CONCLUSÕES}

As informações obtidas mostram que o pegmatito Alto Feio, bem como os demais da PPB são trabalhados de forma artesanal, sem nenhuma orientação técnica, sendo realizadas por garimpeiros que enfrentam muitos tipos de dificuldades. Os garimpos não têm como quantificar a produção devido a sua própria estruturação. Os trabalhos são, às vezes descontínuos e a produção é comercializada quase instantaneamente para vários compradores, com preços variáveis, sem um controle da produção. Apenas as empresas de mineração tem dados sobre produção.

O pegmatito Alto Feio, trabalhado desde a década de 20 do século passado, continua a ser importante no contexto do Seridó, pois ainda é o maior produtor de quartzo róseo da PPB. Foi intensamente trabalhado, como muitos outros da região, durante a II Guerra Mundial para produção de tantalita/columbita e berilo, sem o aproveitamento de outras substâncias minerais úteis. Muitos minerais interessantes, do ponto de vista econômico, estão soterrados no rejeito, como berilo, turmalina negra, entre outros). Alguns minerais industriais importantes, tal como a turmalina negra (schorlita ou dravita) não são aproveitados economicamente. Esses minerais seriam um subproduto importante nesse contexto atual.

É real a possibilidade de redução de sua vida útil do pegmatito, devido principalmente ao modo como vem sendo lavrado, sem nenhuma orientação técnica. Necessita-se de realizar um 
estudo detalhado de pesquisa no pegmatito e também no seu rejeito, com objetivo de aproveitar material, que anteriormente não tinha interesse econômico. Existe também a possibilidade de descoberta de novos minerais econômicos. Para a realização de uma pesquisa necessita-se fazer a remoção de grandes volumes de rejeito que recobrem parte considerável do pegmatito. Essa atividade é onerosa e depende, a nosso ver, de auxílio do setor público, ou da iniciativa privada, pois isso pode representar a geração de vultosos lucros além de ser um problema social a ser resolvido.

\section{AGRADECIMENTOS}

Esse trabalho contou com o apoio do CNPq e do IFPB, através de projeto aprovado no âmbito do Edital 20/2014, PIBIC EM CNPq. Expressamos nossos agradecimentos também aos revisores anônimos.

\section{REFERÊNCIAS}

1. ALMEIDA, S.C. Cobre, estanho e tântalo no Planalto de Borborema. Mineração \& Metalurgia, v.5, n.30, p.277-281, 1941.

2. ALMEIDA, S.C. Tantalita e berilo em Alto Feio e Serra Branca, Estado da Paraíba. DNPM/DFPM (Avulso n. 73). Rio de Janeiro, 29p.,1946.

3. BEURLEN, H., DA SILVA, M.R.R., THOMAS, R., SOARES, D.R., OLIVIER, P. Nb-Ta-(Ti-Sn) oxide mineral chemistry as tracer of rare-element granitic pegmatite fractionation in the Borborema Province, Northeastern Brazil. Mineralium Deposita, v.43, p.207-228, 2008.

4. BEURLEN, H., THOMAS, R., DA SILVA, M.R.R., MÜLlER, A., RHEDE, D., SOARES, D.R. Perspectives for Li- and Ta-mineralization in the Borborema Pegmatite Province, NE-Brazil: a review. Journal of South American Earth Sciences, v.56, p.110-127, 2014.

5. CAMERON, E.N., JAHNS, R.H., McNAIR, A.H.,PAGE, L.R. Internal structure of granitic pegmatites. Economic Geology (Monography, 2). 115p, 1949

6. CERNY, P., Rare-element granitic pegmatites. Part I: Anatomy and internal evolution of pegmatite deposits. Geoscience Canada, v.18, p.49-67, 1991.

7. CERNY, P., ERCIT, T.S. The classification of granitic pegmatites revisited. The Canadian Mineralogist, v.43, p.2005-2026, 2005.

8. DA SILVA, M.R.R. \& DANTAS, J.R.A. A Província Pegmatítica da Borborema-Seridó, nos Estados da Paraíba e Rio Grande do Norte. In: Principais Depósitos Minerais do Nordeste Oriental. DNPM (Séria Geologia, Seção Geologia Econômica, 4). Brasília, p.235-304, 1984.

9. JAHNS, R.H.The study of pegmatites. Economic Geology, 50th Ann., Part II, p.1025-1130, 1955.

10. JOHNSTON Jr., W.D. Beryl-tantalite pegmatites of Northeastern Brazil. Geological Society of América Bulletin, v.56,p.1015-1070, 1945a..

11. JOHNSTON Jr., W.D. Os pegmatitos berilo-tantalíferos da Paraíba e Rio Grande do Norte, no Nordeste do Brasil. DNPM/DFPM (Boletim 72). Rio de Janeiro, 85p.1945b.

12. LONDON, D. Granitic pegmatites. Transactions of the Royal Society of Edinburgh: Earth Sciences,v. 87, p.305-319, 1996. 
13. MELO, R.O.F. A mineração artesanal, e de pequena escala em pegmatitos e cerâmica no município de Parelhas, região do Seridó/Rio Grande do Norte. Dissertação de Mestrado (PRODEMA - Programa Regional de Pós-Graduação em Desenvolvimento e Meio Ambiente), UFRN, Natal, 2011, 94p.

14. MOORE, J.E. Lavra de pegmatitos tantalíferos e gluciníferos no Nordeste do Brasil. DNPM/DFPM (Boletim n. 71). Rio de Janeiro, 51p., 1945.

15. PIRES, A.C.R. Caracterização químico-mineralógica de quartzos do Alto Feio, Pedra Lavrada Paraíba. Dissertação de Mestrado (Pós-Graduação em Geociências) UFPE, Recife, 95p., 1998.

16. ROLFF, P.A.M.A. Bismuto, cobre e ouro na Borborema. DNPM/DFPM (Avulso 75) Rio de Janeiro, 36p., 1946a.

17. ROLFF, P.A.M.A. Reservas minerais do município de Picuí. DNPM/DGM (Boletim 80) Rio de Janeiro, 54p., 1946b.

18. ROLFF, P.A.M.A. Minerais dos pegmatitos da Borborema. DNPM/DFPM (Boletim 78). Rio de Janeiro, 76p., 1946c

19. ROLFF, P.A.M.A. Os pegmatitos da Borborema (notas sobre a sua pesquisa e lavra) Revista Escola de Minas, 4:55-63., 1951.

20. SCORZA, E.P. Província Pegmatítica da Borborema (Nordeste do Brasil). DNPM/DGM (Boletim 112). Rio de Janeiro, 55p.,1944.

21. SOARES, D.R. Contribuição à petrologia de pegmatitos mineralizados em elementos raros e elbaítas gemológicas da Província Pegmatítica da Borborema, NE do Brasil. Tese de Doutorado. UFPE, Recife. 2004, 271p. 